\title{
Relationship of Circulating Cytomegalovirus Levels Obtained Through Antigenemia Testing and Quantitative PCR Differs Between Children and Adults
}

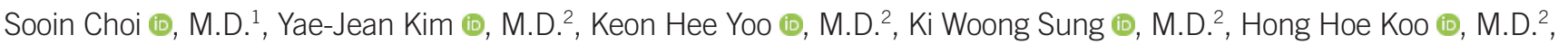

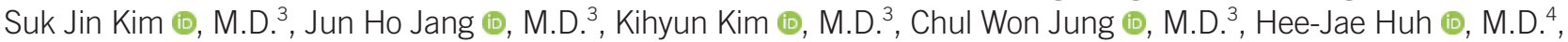 \\ and Eun-Suk Kang $\mathbb{D}$, M.D. ${ }^{4}$ \\ ${ }^{1}$ Department of Laboratory Medicine, Soonchunhyang University Hospital Cheonan, Soonchunhyang University College of Medicine, Cheonan, Korea; \\ ${ }^{2}$ Department of Pediatrics, Samsung Medical Center, Sungkyunkwan University School of Medicine, Seoul, Korea; ${ }^{3}$ Division of Hematology-Oncology, \\ Samsung Medical Center, Sungkyunkwan University School of Medicine, Seoul, Korea; ${ }^{4}$ Department of Laboratory Medicine and Genetics, Samsung Medical \\ Center, Sungkyunkwan University School of Medicine, Seoul, Korea
}

Dear Editor,

Cytomegalovirus (CMV) infection is a major complication in patients who undergo hematopoietic stem cell transplantation (HSCT); thus, surveillance of CMV infection or reactivation is widely performed to prevent disease progression. Although the CMV antigenemia test has long been used for CMV detection [1], it has several limitations such as a requirement for fresh blood samples, subjective interpretation, and reduced feasibility in neutropenic patients [2]. Recently, CMV quantitative (Q)-PCR has emerged as an alternative to antigenemia testing [3]. Nevertheless, there is no universal threshold of circulating DNA values for initiating antiviral therapy in HSCT patients. In addition, the DNA values used to reflect the clinical course may vary among patients because of different therapeutic interventions and age effects. This is the first report to evaluate the relationship of the results of the CMV antigenemia testing and Q-PCR in different age groups of patients undergoing HSCT and to show the impact of age on this relationship. Our results may be useful to establish appropriate threshold values for pediatric and adult patients in similar clinical conditions.
The antigenemia testing (CINA Kit system, Argene Biosoft, Varilhes, France) and Q-PCR (Real-Q CMV DNA quantification kit, BioSewoom, Seoul, Korea) using EDTA-treated whole blood derived DNA (MagNa Pure 96 DNA and Viral NA small volume kit, Roche, Manheim, Germany) were performed simultaneously in HSCT patients to monitor CMV infection at Samsung Medical Center, Seoul, Korea, from June 2016 to December 2017. Retrospective data (2,474 results) were collected from 75 children and 173 adults. The DNA value was generated in standardized units of IU/mL. This study was approved by the Institutional Review Board of Samsung Medical Center (IRB No. SMC 201804-056-001), and informed consent was waived.

The relationship between the results of the antigenemia testing and Q-PCR was analyzed by Deming regression analysis; $P<0.05$ was considered statistically significant. After excluding DNA values outside the linear range or without associated CMV antigenemia results, 516 results were included. The threshold DNA values corresponding to multiple CMV antigenemia values that are considered significant for a clinical decision at our institute were calculated. Youden index were determined through
Received: April 2, 2019

Revision received: May 5, 2019

Accepted: July 11, 2019

Corresponding author: Eun-Suk Kang, M.D.

Department of Laboratory Medicine and Genetics, Samsung Medical Center, Sungkyunkwan University School of Medicine, 81 Irwon-ro, Gangnam-gu, Seoul 06351, Korea

Tel: +82-2-3410-2703, Fax: +82-2-3410-2719, E-mail: eskang@skku.edu

\section{(c) (1) $(9$}

\section{(c) Korean Society for Laboratory Medicine}

This is an Open Access article distributed under the terms of the Creative Commons Attribution Non-Commercial License (http://creativecommons.org/licenses/by-nc/4.0) which permits unrestricted non-commercial use, distribution, and reproduction in any medium, provided the original work is properly cited. 
ROC curve analysis after excluding the upper $5 \%$ and lower $5 \%$ of DNA values, using SAS version 9.4 (SAS Institute Inc., Cary, NC, USA).

The linear regression curves were analyzed using 516 results with significantly different intercepts in the child and adult groups ( $P=0.02$, Fig. 1). The predicted threshold values of CMV DNA that corresponded to clinically significant CMV antigenemia levels of $1,5,10,15,20$, and 25 positive cells/ $2 \times 10^{5}$ white blood cells (WBCs) were 158, 316, 316, 1,122, 1,413, and 1,413 IU/ $\mathrm{mL}$ in children, and 158, 1,995, 2,512, 4,467, 4,467, and 6,310 $\mathrm{IU} / \mathrm{mL}$ in adults, respectively. The proposed optimal thresholds of DNA values and their ability to predict the corresponding CMV
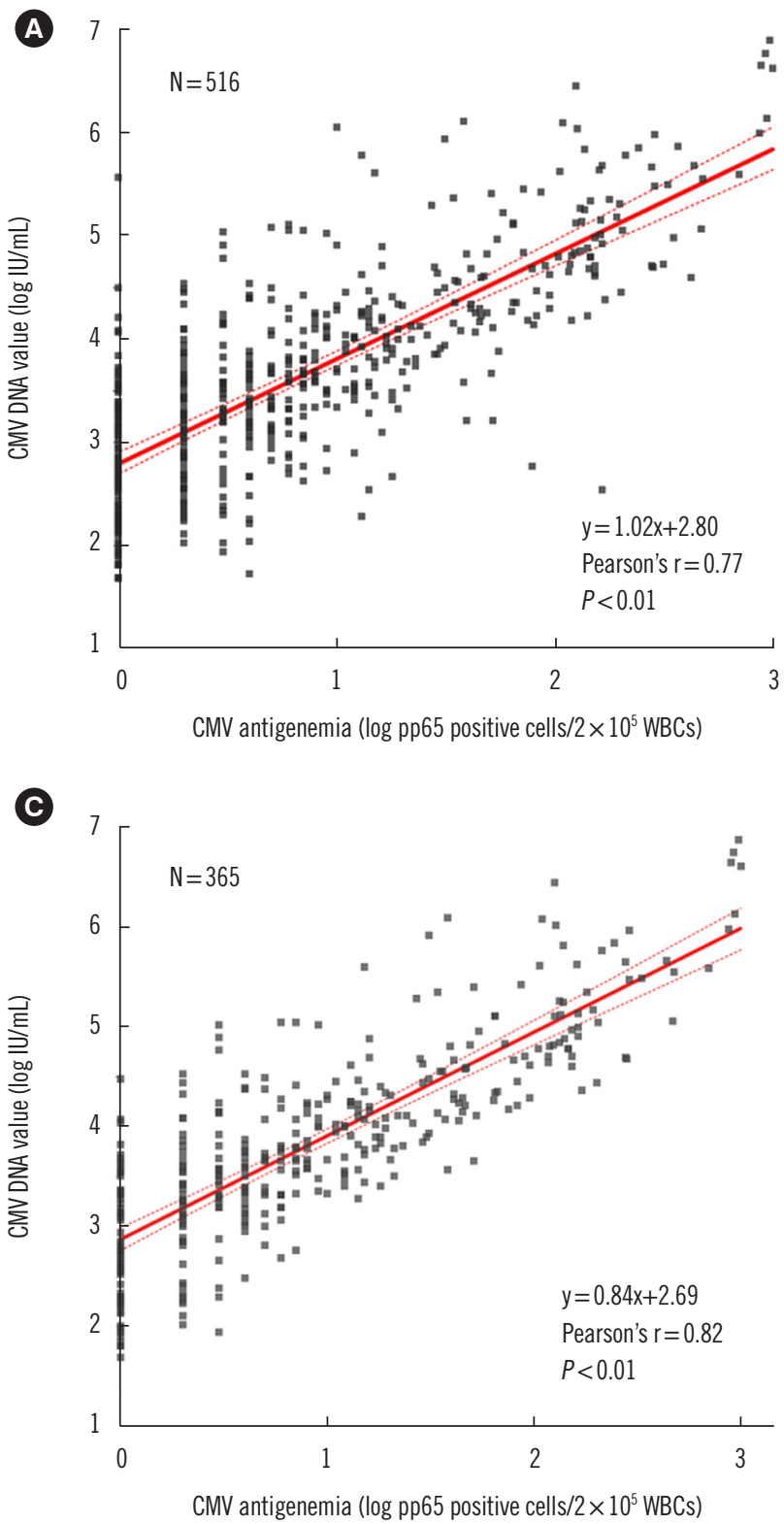

antigenemia levels are presented in Table 1.

Children and adults tend to differ significantly in physiology, metabolic state, physical size, body fluid compartments, and immune responses [4]. Thus, CMV replication kinetics evaluated by different targets (i.e., DNA or antigens) are likely to also differ according to age. Compared with adults, we found that children have significantly lower DNA values over a wide range of CMV antigenemia levels, including clinically significant levels.

Several studies have suggested various threshold DNA values for clinical decision-making depending on the sample used (whole blood [5, 8, 10], plasma [3, 6], and cells [9]) and type of transplant (HSCT [6-10] and solid organ transplantation (SOT) [3, 6,

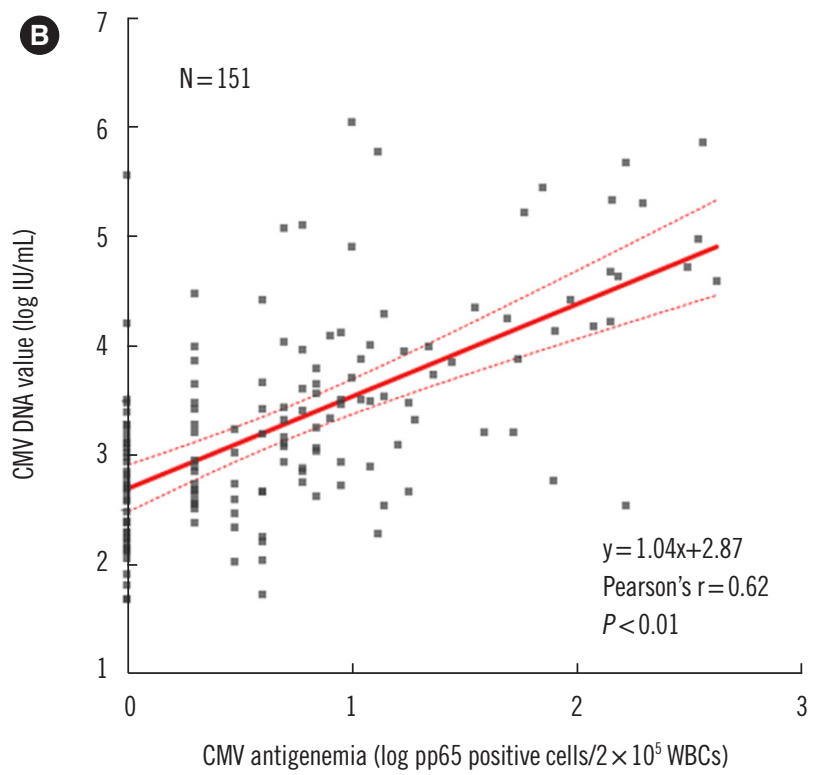

Fig. 1. Relationship between the CMV antigenemia and CMV DNA Q-PCR results in (A) total subjects, $(B)$ children, and $(C)$ adults as determined by Deming regression analysis. The linear regression curves (solid line) showed significantly different intercepts between children and adults $(P=0.02)$. The dashed line represents the $95 \%$ confidence intervals.

Abbreviations: CMV, cytomegalovirus; Q-PCR, quantitative PCR; WBC, white blood cell. 
Table 1. Performance of predicted optimal threshold values of CMV DNA measured by quantitative PCR corresponding to each value of CMV antigenemia in children and adult

\begin{tabular}{|c|c|c|c|c|c|c|}
\hline Patient group & $\begin{array}{l}\text { Patients, N } \\
\text { (Results, N) }\end{array}$ & $\begin{array}{l}\text { Median age, } \\
\text { year (IQR) }\end{array}$ & $\begin{array}{l}\text { CMV antigenemia } \\
\left.\text { (/2 } 2 \times 10^{5} \text { WBCs }\right)\end{array}$ & $\begin{array}{l}\text { Optimal CMV DNA } \\
\text { threshold (IU/mL)* }\end{array}$ & $\begin{array}{l}\text { Sensitivity (\%) } \\
(95 \% \mathrm{Cl})\end{array}$ & $\begin{array}{l}\text { Specificity (\%) } \\
(95 \% \mathrm{Cl})\end{array}$ \\
\hline \multirow[t]{6}{*}{ Children ( $<18$ years) } & $75(746)$ & $8(5-12)$ & 1 & 150 & $85.8(79.6-90.4)$ & $84.4(81.3-87.1)$ \\
\hline & & & 5 & 300 & $98.6(92.5-99.8)$ & $82.6(79.6-85.3)$ \\
\hline & & & 10 & 300 & $97.7(87.9-99.6)$ & $79.2(76.1-82.1)$ \\
\hline & & & 15 & 1,100 & $90.0(74.4-96.5)$ & $89.8(87.4-91.8)$ \\
\hline & & & 20 & 1,400 & $92.0(75.0-97.8)$ & $91.0(88.7-92.9)$ \\
\hline & & & 25 & 1,400 & $91.3(73.2-97.6)$ & $90.7(88.4-92.6)$ \\
\hline \multirow[t]{6}{*}{ Adults ( $\geq 18$ years) } & $173(1,728)$ & $48(36-57)$ & 1 & 150 & $92.9(89.8-95.1)$ & $84.2(82.2-86.1)$ \\
\hline & & & 5 & 2,000 & $95.6(91.8-97.7)$ & $91.7(90.2-93.0)$ \\
\hline & & & 10 & 2,500 & $98.7(95.2-99.6)$ & $91.0(89.4-92.3)$ \\
\hline & & & 15 & 4,500 & 96.7 (91.9-98.7) & $92.9(91.5-94.1)$ \\
\hline & & & 20 & 4,500 & $98.0(93.1-99.5)$ & $91.9(90.5-93.1)$ \\
\hline & & & 25 & 6,300 & 97.9 (92.7-99.4) & 93.6 (92.3-94.7) \\
\hline
\end{tabular}

*Estimated Youden Index through ROC curve analysis.

Abbreviations: CMV, cytomegalovirus; IQR, interquartile range; WBC, white blood cells; Cl, confidence interval.

7]). SOT recipients tended to have higher DNA values than HSCT recipients [6, 7]. Boaretti, et al. [1] suggested 2,275 IU/mL as the threshold DNA value comparable to a CMV antigenemia level of 20 positive cells $/ 2 \times 10^{5}$ WBCs, which differs strikingly from the $4,467 \mathrm{lU} / \mathrm{mL}$ threshold we determined. This difference could be due to variations in the sample type (plasma vs whole blood) or clinical conditions (SOT vs HSCT). These issues need to be further validated by standardization of the sample type for CMV Q-PCR analysis in different patient groups, and eventually by correlation with clinical course or outcome.

In conclusion, we found that relationships of CMV Q-PCR and CMV antigenemia test results differ significantly between children and adults who have undergone HSCT. Thus, threshold DNA values might need to be adjusted according to patient characteristics, to optimize anti-CMV therapeutic efficacy and improve the clinical outcome.

\section{Acknowledgements}

We thank Kyunga Kim and Heejin Yoo from Statistics and Data Center, Research Institute for Future Medicine, Samsung Medical Center, for statistical support.

\section{Author Contributions}

ESK conceived the study; SC and ESK conducted the research described; SC performed the statistical analysis; all authors con- tributed to writing the final manuscript. All authors have accepted their responsibility for the entire content of this manuscript and approved submission.

\section{Conflict of Interest}

None declared.

\section{Research Funding}

None declared.

\section{ORCID}

Sooin Choi

Yae-Jean Kim

Keon Hee Yoo

Ki Woong Sung

Hong Hoe Koo

Suk Jin Kim

Jun Ho Jang

Kihyun Kim

Chul Won Jung

Hee-Jae Huh

Eun-Suk Kang https://orcid.org/0000-0003-4746-4809 https://orcid.org/0000-0002-8367-3424 https://orcid.org/0000-0002-5980-7912 https://orcid.org/0000-0001-5989-4772 https://orcid.org/0000-0001-8082-1412 https://orcid.org/0000-0002-2776-4401 https://orcid.org/0000-0001-7423-4676 https://orcid.org/0000-0002-5878-8895 https://orcid.org/0000-0002-5474-6807 https://orcid.org/0000-0001-8999-7561 https://orcid.org/0000-0001-6386-6520 


\section{REFERENCES}

1. Caliendo AM, St George K, Kao SY, Allega J, Tan BH, LaFontaine R, et al. Comparison of quantitative cytomegalovirus (CMV) PCR in plasma and CMV antigenemia assay: clinical utility of the prototype AMPLICOR CMV MONITOR test in transplant recipients. J Clin Microbiol 2000;38: 2122-7.

2. Bontant T, Sedlacek P, Balduzzi A, Gaspar B, Cesaro S, Einsele H, et al. Survey of CMV management in pediatric allogeneic HSCT programs, on behalf of the inborn errors, infectious diseases and pediatric diseases working parties of EBMT. Bone Marrow Transplant 2014;49:276-9.

3. Boaretti M, Sorrentino A, Zantedeschi C, Forni A, Boschiero L, Fontana R. Quantification of cytomegalovirus DNA by a fully automated real-time PCR for early diagnosis and monitoring of active viral infection in solid organ transplant recipients. J Clin Virol 2013;56:124-8.

4. Tahmasebi H, Higgins V, Fung AWS, Truong D, White-Al Habeeb NMA, Adeli K. Pediatric reference intervals for biochemical markers: gaps and challenges, recent national initiatives and future perspectives. EJIFCC 2017;28:43-63.

5. Li H, Dummer JS, Estes WR, Meng S, Wright PF, Tang YW. Measurement of human cytomegalovirus loads by quantitative real-time PCR for monitoring clinical intervention in transplant recipients. J Clin Microbiol
2003;41:187-91.

6. Kalpoe JS, Kroes AC, de Jong MD, Schinkel J, de Brouwer CS, Beersma MF, et al. Validation of clinical application of cytomegalovirus plasma DNA load measurement and definition of treatment criteria by analysis of correlation to antigen detection. J Clin Microbiol 2004;42:1498504.

7. Cariani E, Pollara CP, Valloncini B, Perandin F, Bonfanti C, Manca N Relationship between pp65 antigenemia levels and real-time quantitative DNA PCR for human cytomegalovirus (HCMV) management in immunocompromised patients. BMC Infect Dis 2007;7:138.

8. Choi SM, Lee DG, Lim J, Park SH, Choi JH, Yoo JH, et al. Comparison of quantitative cytomegalovirus real-time PCR in whole blood and pp65 antigenemia assay: clinical utility of CMV real-time PCR in hematopoietic stem cell transplant recipients. J Korean Med Sci 2009;24:571-8.

9. Peres RM, Costa CR, Andrade PD, Bonon SH, Albuquerque DM, de Oliveira $\mathrm{C}$, et al. Surveillance of active human cytomegalovirus infection in hematopoietic stem cell transplantation (HLA sibling identical donor): search for optimal cutoff value by real-time PCR. BMC Infect Dis 2010; 10:147.

10. Kwon S, Jung BK, Ko SY, Lee CK, Cho Y. Comparison of quantitation of cytomegalovirus DNA by real-time PCR in whole blood with the cytomegalovirus antigenemia assay. Ann Lab Med 2015;35:99-104. 